\title{
先进铜合金材料发展现状与展望
}

\author{
姜业欣 ${ }^{1,2}$, 娄花芬 ${ }^{3}$, 解浩峰 ${ }^{4}$, 李廷举 ${ }^{5}$, 宋克兴 ${ }^{6}$, 刘雪峰 ${ }^{7}$, 运新兵 ${ }^{8}$, 汪航 ${ }^{9}$, 肖柱 ${ }^{1}$, 李周 ${ }^{1}$ \\ (1. 中南大学材料科学与工程学院, 长沙 410083; 2. 中色奥博特铜铝业有限公司, 山东聊城 252600; 3. 中铝材料应用 \\ 研究院有限公司, 北京 102209; 4. 有研工程技术研究院有限公司, 北京 101407; 5. 大连理工大学材料科学与工程 \\ 学院, 辽宁大连 116024; 6. 河南科技大学材料科学与工程学院, 河南洛阳 471003; 7. 北京科技大学材料 \\ 科学与工程学院, 北京 $100083 ; 8$. 大连交通大学连续挤压教育部工程研究中心, 辽宁大连 116028; \\ 9. 江西理工大学材料科学与工程学院, 江西赣州 341000)
}

摘要: 本文针对我国电工电子、新一代移动通信、新能源汽车、航空航天、轨道交通等新兴产业和重大工程领域对先进铜合 金材料的典型需求，梳理了国内外高强高导铜合金、耐磨耐蚀铜合金、超高强弹性铜合金、先进铜基复合材料、高精度铜及 铜合金细微丝、超薄筞材的发展现状和差距。在此基础上分析了上述先进铜合金的典型市场需求, 论证了我国先进铜合金材 料的中长期发展目标和关键技术。研究还提出了促进 “产学研用管” 的统筹规划和一体化发展, 提升装备开发、技术研发和 市场拓展能力, 强化产品标准研究与制定, 建立青年科技骨干人才培养体系的产业发展建议。期望以国民经济重点领域和国 防建设需求为导向，通过铜合金材料、装备、技术、产业化等自主创新体系的完善，促进我国先进铜合金材料绿色、高端、 智能发展。

关键词: 铜合金; 高强度; 高精度; 功能应用

中图分类号: TG146.2 文献标识码: A

\section{Development Status and Prospects of Advanced Copper Alloy}

\author{
Jiang Yexin ${ }^{1,2}$, Lou Huafen ${ }^{3}$, Xie Haofeng ${ }^{4}$, Li Tingju ${ }^{5}$, Song Kexing ${ }^{6}$, Liu Xuefeng ${ }^{7}$, \\ Yun Xinbing ${ }^{8}$, Wang Hang ${ }^{9}$, Xiao Zhu ${ }^{1}$, Li Zhou ${ }^{1}$
}

(1.School of Materials Science and Engineering, Central South University, Changsha 410083, China; 2. CNMC Albetter Copper

Co., Ltd., Liaocheng 252600, Shandong, China; 3. ChinaLCO Materials Application Research Institute Co., Ltd., Beijing 102209,

China; 4. GRIMAT Engineering Institute Co., Ltd., Beijing 101407, China; 5. School of Materials Science and Engineering,

Dalian University of Technology, Dalian 116024, Liaoning, China; 6. School of Materials Science and Engineering, Henan

University of Science and Technology, Luoyang 471003, Henan, China; 7. School of Materials Science and Engineering,

University of Science and Technology Beijing, Beijing 100083, China; 8. Engineering Research Center of Continuous

Extrusion, Ministry of Education, Dalian Jiaotong University, Dalian 116028, Liaoning, China; 9. School of Materials Science and Engineering, Jiangxi University of Science and Technology, Ganzhou 341000, Jiangxi, China)

\begin{abstract}
Based on the typical demand for advanced copper alloys by emerging industries and major engineering projects, such as electrical engineering, electronics, 5G communications, new energy vehicles, aerospace, and rail transit, this study systematically summaries the current status of international and domestic copper alloy industries, including high-strength and high-conductivity
\end{abstract}

收稿日期 : 2020-07-26; 修回日期 : 2020-09-02

通讯作者: 娄花芬, 中铝材料应用研究院有限公司教授级高级工程师, 研究方向为铜、镁有色金属新材料及制备技术; E-mail:louhuafen@163.com

资助项目：中国工程院咨询项目“新材料强国 2035 战略研究” (2018-ZD-03)

本刊网址： www.engineering.org.cn/ch/journal/sscae 
copper alloy, wear and corrosion resistance copper alloy, elastic copper alloy with ultra-high strength, advanced copper matrix composites, and copper alloy wires and foils with high precision. The typical market demand of the advanced copper alloys is analyzed and the medium and long-term development goals and key technologies of the copper alloy materials in China are proposed. Moreover, industrial development suggestions are also proposed including promotion of the overall planning and integrated development of production, research, application, and management; enhancement of equipment development, technology development, and market expansion abilities; improvement in the research and formulation of product standards; and establishment of a training system for young scientists and technicians. This study is expected to promote the green, high-end, and intelligent development of advanced copper alloy materials in China through the improvement in independent innovation system regarding the copper alloy materials, equipment, technology, and industrialization, thus to meet the demands of national economy and national defense construction.

Keywords: copper alloy; high strength; high precision; functional application

\section{一、前言}

《国家中长期科学和技术发展规划纲要》《新 材料产业发展指南》等政策文件明确提出, 新一代 信息技术、先进轨道交通装备、航空航天装备、节 能与新能源汽车等产业是我国重点发展的高新技术 领域。这些领域的关键基础材料之一是高性能铜合 金。高性能铜合金具有高导电性、高导热性、高强 度、高耐蚀以及可镀性和易加工性等一系列优异性 能 [1], 是上述领域发展不可或缺的材料类型。

我国铜材产量和消费量均居世界首位。按照包 括各种常用铜材在内的总体产量和进口量计算, 通 用铜材的国内满足度达到了 $96 \%$ 。先进铜合金材 料与构件在国家安全、重大工程和经济建设中具 有重要地位, 然而各种高性能铜合金材料严重依 赖进口，如新型高强高导铜合金带材、超细丝材、 超薄带材等。

开发先进铜合金材料及其高效、短流程制备加 工新技术对促进战略新兴产业发展、推动我国由材 料大国向材料强国迈进起着重要的支撑作用。本文 从国家重大工程和新兴产业用铜合金的应用着手, 梳理诸多领域内铜合金材料的发展与应用现状，在 分析先进铜合金材料的研发趋势与典型市场需求的 基础上, 提出先进铜合金材料的中长期发展目标与 建议。

\section{二、国内外铜合金材料应用现状}

随着高新技术产业的飞速进步，新材料朝着超 高性能、高纯度、高迭代方向发展 [2], 对相关产 品的集成化、功能化、微型化、可靠性等提出了更
高要求。先进铜及铜合金作为核心导体材料, 广泛 用于电子信息产业超大规模集成电路引线框架, 国 防装备的电子对抗、雷达、大功率微波管, 高脉冲 磁场导体材料, 高速轨道交通用架空导线、大功率 调频调速异步牵引电动机导条与端环, 新能源汽车 用电阻焊电极、电池材料、充电桩弹性材料, 治金 工业用连铸机结晶器、电真空器件, 电气工程用开 关触桥和各种导线等。

\section{（一）高强高导铜合金}

高强高导铜合金主要应用于集成电路引线框架 带材、轨道交通接触线、高压电器触头等部件。国 际市场上的高强高导铜合金材料有百余种, 获得广 泛应用的主要是 $\mathrm{Cu}-\mathrm{Fe}-\mathrm{P}$ 系、 $\mathrm{Cu}-\mathrm{Ni}-\mathrm{Si}$ 系、 $\mathrm{Cu}-\mathrm{Cr}-$ $\mathrm{Zr}$ 系等。

在 $\mathrm{Cu}-\mathrm{Fe}-\mathrm{P}$ 系、 $\mathrm{Cu}-\mathrm{Ni}-\mathrm{Si}$ 系合金方面, 国外开 发了系列牌号，如美国环球金属制品有限公司的 C19400 (CuFeP) 和 C70250 ( CuNiSi), 日本三菱 伸铜株式会社的 TAMAC194 ( CuFeZnP)、古河电 气工业株式会社的 EFTEC6 ( $\mathrm{CuFeP})$ 、神户制钢株 式会社的 KLF5 (CuFeSnP) 和 KLF118 ( CuNiSiZn)、 日矿金属株式会社的 NKC114（CuNiSiZn）等。关 于引线框架带材, 目前应用最广泛的仍是美国环球 金属制品有限公司最早开发的中强高导型 $\mathrm{Cu}-\mathrm{Fe}-\mathrm{P}$ 系合金（如 C19400、 $\mathrm{KFC}$ 等），具有成本低廉、强 度中等、高导电性、高导热性和良好的钎焊性、浸 润性、加工成型性等优良特性。中铝洛阳铜业有限 公司、中铜华中铜业有限公司、宁波兴业盛泰集团 有限公司和宁波博威合金材料股份有限公司等已经 实现了 C19400 合金的商品化生产，占据了国内的 主要市场份额。国内高校和企业还开展了协同攻关, 
在保证 Cu-Fe-P 合金材料综合性能的前提下, 将抗 软化温度提高了近 $50{ }^{\circ} \mathrm{C}[3]$ 。宁波兴业盛泰集团有 限公司、中铝洛阳铜业有限公司、宁波博威合金 材料股份有限公司、宁夏东方钽业股份有限公司 等实现了 C70250 合金带材产业化。

$\mathrm{Cu}-\mathrm{Cr}-\mathrm{Zr}$ 系合金是高速轨道交通接触线和超 大规模集成电路引线框架的理想材料。日本奈川株 式会社研发的 PHC-120 接触导线就属于该合金体 系。近年来, 美国、日本和德国企业相继开发了耐 热 $\mathrm{Cu}-\mathrm{Cr}-\mathrm{X}$ 系合金引线框架带材, 如 $\mathrm{KME}$ 集团的 C18160、维兰德集团的 C18080、三菱伸铜株式会 社的 $\mathrm{C} 18141$ 等, 抗拉强度为 $540 \sim 630 \mathrm{MPa}$, 导电 率为 79\% 84\% IACS (国际退火铜标准)。国内在 $\mathrm{Cu}-\mathrm{Cr}-\mathrm{Zr}$ 系合金的成分优化和组织结构调控等方面 进行了系统研究 [4], 宁波博威合金材料股份有限 公司等实现了具有自主知识产权的 $\mathrm{Cu}-\mathrm{Cr}-\mathrm{Zr}$ 系合金 带材产业化。

\section{（二）耐磨耐蚀铜合金}

常用耐磨耐蚀铜合金包括锡青铜、铝青 铜、锰白铜和复杂黄铜, 铸件的抗拉强度为 400 $500 \mathrm{MPa}$, 硬度为 100 200 HBS (布氏硬度), 延伸 率为 $6 \% \sim 10 \%$; 挤压材的抗拉强度可达 $600 \mathrm{MPa}$, 硬度超过 $200 \mathrm{HBS}$ 。国外主要生产商有日本三宝伸 铜株式会社、住友重机械工业株式会社, 国内有中 铝洛阳铜业有限公司、洛阳双瑞达特铜有限公司。

海洋工程用 $\mathrm{CuNi}$ 系耐蚀铜合金主要是 $\mathrm{B} 10$ $(\mathrm{Cu}-10 \mathrm{Ni}-1 \mathrm{Fe}-1 \mathrm{Mn})$ 和B30 ( Cu-30Ni-1Fe-1Mn) 合 金。德国、韩国生产的海洋工程用无缝耐蚀白铜排 水管的最大直径超过 $520 \mathrm{~mm}$, 壁厚最薄达 $0.7 \mathrm{~mm}$ 。 国内在大口径耐蚀白铜管研制方面起步较晚, 存在 耐蚀性不稳定、使用寿命低的问题, 部分高端耐蚀 $\mathrm{Cu}-\mathrm{Ni}-\mathrm{Fe}$ 合金管材产品依赖进口。CuNiSn 系合金 的抗拉强度可达 $1000 \mathrm{MPa}$, 且耐蚀性能优异, 在 海水或酸性、油气环境下的耐蚀性能以及高负载条 件下的耐磨性能均优于铍铜、铝青铜。目前国内所 用的高端超高强 CuNiSn 系合金全部依赖进口, 其 中美国 Materion 集团、日本永木精械株式会社、 克拉尔特种金属 (法国) 有限公司的产品处于市 场主导地位。国内相关机构正在联合攻关大规格 $\mathrm{CuNiSn}$ 合金特殊铸造环境下的铸坏连续铸造技术
及成套装备、合金形变热处理制度、变形组织结 构和内应力分布特征及其调控技术, 奠定了该合金 的国产化基础。

\section{（三）超高强弹性铜合金}

超高强弹性铜合金一般指具有 $1000 \mathrm{MPa}$ 以上 强度、125 GPa 以上弹性模量的铜合金。高可靠性 连接器用弹性铜合金主要是铍铜合金。工业发达国 家在铍铜合金材料的生产和应用方面达到了极高水 平, 且相关装备与生产技术仍在革新; 尤其是美国 (以 Materion 集团为代表) 和日本 (以永木精械株 式会社为代表) 企业的生产规模都很大, 生产技术 和装备水平处于世界领先地位。

铍铜合金含剧毒物质铍, 在高于 $150{ }^{\circ} \mathrm{C}$ 环境下 的应力松弛率急剧增大, 极易导致弹性元器件在工 作状态下的接触压力发生改变, 致使连接器工作失 效。开发新型的环保超高强、高抗应力松弛、成形 性能优良、可靠性高的导电弹性铜合金成为弹性材 料研究热点。C $\mathrm{Cu}-\mathrm{Ni}-\mathrm{Mn}$ 、 $\mathrm{Cu}-\mathrm{Ti}$ 和 $\mathrm{Cu}-\mathrm{Ni}-\mathrm{Sn}$ 等合金 均属于时效强化型合金, 经过形变热处理后, 可获 得与铍铜合金相謧美的强度和弹性性能以及更加优 越的耐腐蚀和抗应力松弛性能 $[5,6]$ 。这些合金相继 由法国、美国、日本等企业研究开发, 已部分替代 铍铜合金的产业应用。国内部分铜加工企业正在试 制 $\mathrm{Cu}-\mathrm{Ti}$ 合金产品, 但规模化生产的关键加工制备 技术仍待全面突破, 导致现有 $\mathrm{Cu}-\mathrm{Ti}$ 合金材料无法 实现自给。

\section{（四）先进铜基复合材料}

先进铜基复合材料是液氢/液氧火箭发动机内 祄、超高压开关、电极等部件的关键用材。在高导 铜基复合材料方面, 引入碳纳米管和石墨烯, 发 展高强度、高电导率的碳纳米管/石墨烯增强铜基 复合材料成为国内外研发的前沿方向之一。实验 室制备的该系列铜基复合材料样品, 抗拉强度大于 $500 \mathrm{MPa}$, 导电率达到 $115 \%$ IACS。在抗电磁屏蔽 铜基复合材料方面, 日本企业开发了系列 CFA 合 金, 如 CFA95 对磁场具有 $50 \sim 80 \mathrm{~dB}$ 的屏蔽效果, 对电场具有超过 $80 \mathrm{~dB}$ 的屏蔽效果, 同时自身导电 率为 $60 \%$ 70\% IACS。陕西斯瑞新材料股份有限公 司、宁波金田铜业 (集团) 股份有限公司等国内企 
业也在兴建 $\mathrm{CuFe}$ 合金制造基地。

在高强高导抗高温退火软化铜基复合材料 方面, 美国 SCM 金属制品有限公司开发了多种 $\mathrm{Cu}-\mathrm{Al}_{2} \mathrm{O}_{3}$ 弥散强化铜合金的牌号 (如 $\mathrm{C} 15710$ 、 C15720、C15760 等), 具有较大的生产规模。 $\mathrm{Cu}-\mathrm{Al}_{2} \mathrm{O}_{3}$ 弥散强化铜合金材料的耐热温度高达 $900{ }^{\circ} \mathrm{C}[7]$, 主要用作电焊电极、医疗影像器件和电 真空器件材料。中铝洛阳铜业有限公司、有研工程 技术研究院有限公司等国内机构也分别推出了自主 研发的弥散强化铜合金产品, 主要用于汽车镀层钢 板、电池镍片、铝及铝合金的焊接电极等。此外, 一些特种功能的铜基复合材料也得到应用, 如抗电 蚀 $\mathrm{CuCr}$ 触头材料、高导热低膨胀 $\mathrm{CuW}$ 电子封装材 料、超高强高导 $\mathrm{Cu}-\mathrm{Nb}$ 复合材料（室温抗拉强度可

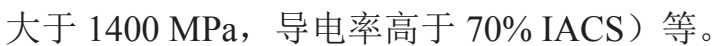

\section{（五）高精度铜及铜合金细微丝、超薄箔材}

微电子及超微电子、新一代移动通信、智能 机器人等产品的普及率不断提升, 对超精细高性 能铜丝、高性能超薄铜䈃的需求越来越大。在细 微丝方面, 国内市场不同规格铜细微线的供需关 系存在巨大差别: 直径 $0.04 \mathrm{~mm}$ 以上的铜导线 供大于求，价格低廉、竞争激烈; 超细（直径为 0.015 0.04 mm) 铜导线的国内需求大于生产能力, $60 \%$ 以上依靠进口; 直径在 $0.015 \mathrm{~mm}$ 以下的超精 细铜导线则基本依赖进口。近年来, 国内一些厂 家启动了铜细微丝研发工作，但受限于设备和技 术, 产品成材率低、性能不均一, 尚不能满足微 电子行业的需求。

在超薄箔材方面，国内许多高档覆铜板、印制 电路板生产企业所必需的高挠曲性、高机械强度压 延铜䈃，多数供应被日矿金属株式会社、福田金属 箔粉工业株式会社、美国环球金属制品有限公司和 日立电线株式会社等国外企业所主导。目前，高挠 曲性压延铜箔已实现箔材厚度 $\leqslant 33 \mu \mathrm{m}$ 时、室温下 的抗拉强度 $\geqslant 500 \mathrm{MPa}$, 在 $135^{\circ} \mathrm{C} 、 30 \mathrm{~min}$ 热处理 条件下的抗拉强度 $\geqslant 150 \mathrm{MPa}$ 、延伸率 $\geqslant 10 \%$ 、挠 曲次数 $\geqslant 7.6 \times 10^{8}$ 次。中色奥博特铜铝业有限公司、 灵宝华金铜䈃有限责任公司等国内企业可以规模化 生产部分规格的高品质压延铜䈃。在压延铜䈃的表 面处理方面, 国内企业仅初步掌握灰化处理技术, 而黑化处理技术仍待研发。

\section{三、我国先进铜合金材料应用需求分析}

\section{（一）高强高导铜合金}

近年来，以铜镁、铜银、铜铬系合金为代表 的高强高导铜合金的产业化技术取得了突破, 在导 电率保持在 $80 \%$ IACS 以上水平的同时, 强度较纯 铜提高数十倍, 大幅提升产品性能; 在超大规模 集成电路引线框架、电气化铁道接触网用接触线、 高端精密电线电缆等方面获得广泛应用 [8]。例 如, 高强高导 $\mathrm{Cu}-\mathrm{Ni}-\mathrm{Si}-(\mathrm{Co})$ 系合金的抗拉强度为 $700 \sim 900 \mathrm{MPa}$ 、导电率为 45\% 55\% IACS [9]; 国 内部分铜加工企业已经开展试生产及小批量市场供 货，预计 2020 年后得到大量应用。

高强高导 $\mathrm{Cu}-\mathrm{Cr}-\mathrm{Zr}$ 系合金是轨道交通接触网 线、航空航天线缆、大规模集成电路引线框架、汽 车工业和电子控制系统、电焊电极、高脉冲磁场导 体、大型高速涡轮发电机转子导线等部件的理想材 料。我国 $300 \mathrm{~km} / \mathrm{h}$ 及以下速度的高速铁路接触网线 主要有 $\mathrm{Cu}-\mathrm{Ag}$ 线、 $\mathrm{Cu}-\mathrm{Sn}$ 线、 $\mathrm{Cu}-\mathrm{Mg}$ 线, 已实现自 给自足; $380 \mathrm{~km} / \mathrm{h}$ 及以上速度的高速铁路接触网线 试验线路采用 $\mathrm{Cu}-\mathrm{Cr}-\mathrm{Zr}$ 合金接触线，包括京沪高速 铁路柊庄至蛙埠高速试验段、大西高速铁路太原北 至原平西高速试验段。铁道行业标准 TB/T28092017 《电气化铁道用铜及铜合金接触线》 [10] 明确 了 $\mathrm{Cu}-\mathrm{Cr}-\mathrm{Zr}$ 系合金接触线产品标准, 为后续推广应 用扫清了障碍。

新一代电子信息技术集成电路引线框架、未来 柔性电网材料都对高导高强的 Cu-Cr-Zr 系合金板/ 带/䈃提出了迫切需求。引线框架带材是集成电路的 芯片载体，是电子信息产业中重要的基础材料。预 计到 2035 年, $\mathrm{Cu}-\mathrm{Cr}$ 系合金在高速铁路接触线应用 可替代超过 $60 \%$ 的同类普通材料，在引线框架铜 合金应用可替代超过 30\% 的同类普通材料。

\section{（二）耐磨耐蚀铜合金}

耐蚀铜合金广泛应用于海水淡化、舰船、海上 石油平台等领域用冷凝器、热交换器管材和各种高 强耐蚀件 (阀体、法兰、接头等)。随着我国航空 航天、机械制造行业的快速发展, 航空发动机、高 速轴承等部件对高强耐磨耐蚀耐热铜合金的性能要 求和需求量显著提高。 $\mathrm{Cu}-\mathrm{Ni}-\mathrm{Sn}$ 系合金抗拉强度可 达 $1000 \mathrm{MPa}$, 耐蚀性能优于铍铜、铝青铜, 是航空、 
重载装备、石油化工、高档数控机床、机器人等核 心零组件的关键基础材料。这类材料的应用对象有: 民航飞机起落架、翼型控制轴承、轴套及液压系统 耐磨部件, 重型装备、数控机床和汽车的气门导管、 凸轮滚动销轴、滚子轴承, 液压柱塞泵的缸体、配 流盘、柱塞、轴套、磨耗增强板、成形辊/冲头等。

\section{（三）超高强弹性铜合金}

超高强弹性铜合金一般要求材料抗拉强度 $\geqslant 1000 \mathrm{MPa}$, 弹性模量 $\geqslant 130 \mathrm{GPa}$ 。对于铍铜（如 $\mathrm{QBe} 2$ 和 C17200 等）板带材产品, 有 $60 \%$ 用于制 造弹性元件, 如膜片、波纹管、发电机刷弹簧、继 电器弹簧、弹簧接触片、断路器弹簧、航空仪表用 各类弹簧; 还用于精密仪器制造, 轴承、齿轮、双 辊连续铸轧铝板坏用辊套、特殊的无火花工具制造 等; 在电动车充电桩、海洋工程用通信装备方面 也有广阔的市场需求。目前全球铍铜板带材供不 应求的形势更显突出, 年需求量以约 $12 \%$ 的速度 增长; 国内市场年需求量更是以 $20 \% \sim 39 \%$ 的速度 增长, 且高精度板带材（厚度小于 $0.4 \mathrm{~mm}$ ) 仍然 依赖进口。

近年来, 超高强弹性铜合金朝着高抗应力松弛 环保型弹性铜合金方向发展, 如 $\mathrm{Cu}-\mathrm{Ni}-\mathrm{Co}-\mathrm{Si} 、 \mathrm{Cu}-$ Ti、Cu-Ni-Sn 系合金等。国内团队研究发现 [11], 经多级形变热处理后的 $\mathrm{Cu}-\mathrm{Ni}-\mathrm{Co}-\mathrm{Si}$ 系合金抗拉强 度可达 $1086 \mathrm{MPa}$ 、导电率超过 30\% IACS。钛青铜 具有高的强度和弹性、优良的耐磨性, 无磁性、易 软钎焊和电镀, 碰击时不产生火花, 可用于高强度、 高弹性、高耐磨性元件, 如电器开关、继电器弹性 元件、精密小型齿轮、各种轴承等。QTi6-1 合金耐 高温性能优于铍青铜, 可代替用作精密仪器和仪表 的弹性元件, 如振动变流器的振动片和膜片、超高 频标准器的接触弹性元件、行程开关弹片、新能源 汽车/电子产品用高性能连接器等。预计到 2035 年, QTi6-1 合金可实现对铍铜合金材料约 70\% 的替代。

\section{（四）先进铜基复合材料}

具有高强、高导、耐高温、耐电蚀、抗电磁屏 蔽等特性的铜基复合材料成为众多高端装备的亟需 材料, 包括相控阵雷达、大功率高频脉冲磁场、大 功率电子器件封装、液氢/液氧火箭发动机内祄、
超高压开关触头、电焊电极触头等。

新一代铜铁电磁屏蔽材料( $\mathrm{Fe}$ 含量为 $5 \%$ 40\%) 是新型显示器的关键材料, 导电率高、散热性好, 具有电磁屏蔽功能, 在计算机、通信、汽车、电子、 航天、航空等领域的电磁兼容方面应用广泛; 在医 疗设备、医院等场所用于电磁场屏蔽, 在通信、电 力等领域用作电磁屏蔽材料。

通过引入石墨烯或纳米陶瓷颗粒形成具有特种 功能的铜基复合材料也进一步获得应用。 $\mathrm{Cu}-\mathrm{Al}_{2} \mathrm{O}_{3}$ 弥散强化铜合金具有优异的抗高温软化性能, 在雷 达、电子对抗、遥控遥测、粒子加速器等设备中的 微波管内腔体、发射管栅支持杆、行波管慢波线、 电阻焊电极等方面具有广阔应用前景。

在电加工领域, 采用铇铜合金作为触头材料成 为主流。铇铜合金成本相对低廉, 具备高导热、高 导电、高耐热、低热膨胀、高耐电流侵蚀的特性, 满足高功率、高电压、大电流接触类材料的性能要 求, 广泛用作大规模集成电路中的基片材料和芯 片散热材料。

\section{（五）高品质超细导电铜合金线}

超细导电铜合金线作为关键基础材料，用于制 备集成电路封装导线、微型电机输电线、高频超细 同轴电线、高速宽频传输线缆、通信终端传输线和 医用精密导线等。目前超细铜线材主要有 $\mathrm{Cu}-\mathrm{Ag}$ 、 $\mathrm{Cu}-\mathrm{Sn}$ 系合金。微细电磁线是电子元器件中极为重 要的电流载体, 其导电线芯要求有极高的导电率和 良好的力学性能以满足电子元器件的制造工艺要 求; 主要用于微特电机、继电器、电子变压器、互 感器、电磁阀等电子元器件, 涉及智能机器人、交 通运输、仪器仪表、国防军工等装备应用。

无氧铜、银铜合金等超细丝材是高新技术产业 用微型电机的关键材料。例如, 对于微型电机线圈 绕组、电磁线芯等, 丝材直径普遍小于 $80 \mu \mathrm{m}$, 制 备加工难度较大。随着国内原材料制备技术和装备 能力的提升, 直径小于 $30 \mu \mathrm{m}$ 的超细线制备技术研 究有所进展。预计到 2035 年, 国产同类产品对进 口产品的替代率超过 $50 \%$ 。

\section{（六）高强高导压铸铜合金材料}

目前我国各类电动机的耗电量占社会总用电 
量的 $60 \%$ 左右。大多数鼠笼型三相异步电动机使 用的铸铝转子, 体积大、能耗高、效率低, 是电动 机功率损失的重要部件, 严重制约了电动机效率提 升。铜具有良好的导电性、散热性和耐磨性, 以铸 铜转子来替代铸铝转子成为研发超高效率电动机的 可行方向。在研的铸铜转子转速低于 $3000 \mathrm{r} / \mathrm{min}$, 可用于减速机、水百等工业电机; 但相关制备工 艺尚不稳定, 成材率低、缺陷多, 涉及的关键技 术有待攻克。在电动汽车及中主轴用电动机方面, 因转速高于 $8000 \mathrm{r} / \mathrm{min}$, 对铜转子提出了高致密、 高强度等更严格要求, 后续需进一步开发保持高 导电率、兼具高屈服强度和抗拉强度的铜合金压 铸材料。

\section{（七）电子用超薄压延铜箔}

柔性电路板是有机发光二级管 (OLED) 屏幕 中不可或缺的配件, 而压延铜䇴是制造屏蔽材料、 柔性印刷线路板、石墨烯透明导电薄膜的重要材料。 目前, OLED 屏幕已被手机广泛采用, 未来随着可 穿戴电子设备、高分辨率显示装置、折叠显示屏、 智能医疗、无人驾驶等科技的普及，鉴于柔性电路 板的极高性能要求, 压延铜箔的使用比例将会越来 越高。

根据中国电子材料协会统计，2016 年全国柔 性覆铜板 (FCCL) 产量达到 $5.464 \times 10^{7} \mathrm{~m}^{2}$, 其中 压延铜箔使用量约为 $4600 \mathrm{t}$, 年均增长率为 $19.9 \%$ 。 2017 年全球压延铜箔产量为 $6.9 \times 10^{4} \mathrm{t}$, 而我国 4 家 主要企业（中色奥博特铜铝业有限公司、山东天和 压延铜箔有限公司、灵宝金源朝辉铜业有限公司、 苏州福田金属有限公司）的总产量仅约为 $7 \times 10^{3} \mathrm{t}$ 。 按此估算, 到 2035 年, 我国高性能压延铜䈃替代 国外材料的比例有望达到 $40 \%$ 。

\section{（八）环保易切削系列铜合金材料}

铅黄铜广泛应用于电子电气、水管龙头、阀体、 钟表、锁具、玩具、接插件、耐磨件等方面。铅为 有毒元素, 众多国家设立相关法案对铅黄铜在电子 电气设备、供水系统方面的使用进行了限制, 开发 环保易切削铜合金成为必然发展趋势。现有的供应 替代有铋黄铜、硅黄铜等。铋黄铜, 如 C89XXX (美国)、BZ5/BZ3（日本三越金属株式会社）、
HB-20（浙江海亮股份有限公司）、HBi60（四川 金炬矿业资源开发股份有限公司)、ZHBi87（宁波 博威合金材料股份有限公司）等，材料成本高，易 出现应力开裂和应力腐蚀现象。硅黄铜的铜含量为 $70 \% \sim 80 \%$, 成本较高, 如 ECO BRASS（日本三菱 伸铜株式会社), HSi80-3、HSi75-3 (中国) 等。其 他材料, 如锑黄铜、镁黄铜、磷钻黄铜、石墨黄铜 等尚未得到大规模的推广应用。

环保易切削铜合金未来发展趋势是开发切削性 优异的低成本铜合金。预计到 2035 年，在电子电 气设备、供水系统方面的环保易切削铜合金替代量 将达到 $60 \%$ 。

\section{四、我国先进铜合金材料的研发趋势与面临 问题}

\section{（一）技术研发趋势}

近年来，我国高性能铜合金及其制备技术的整 体水平取得了长足进步，拥有自主知识产权的高性 能铜合金产品种类不断增加，铜合金材料加工装机 水平已接近国际先进水平。先进铜合金材料的研发 和产业化的发展趋势呈现如下特点。

（1）由单一性能要求朝着多功能特性要求的方 向发展。例如, 兼具高导热、高电磁屏蔽性能的铜 基材料应满足脉冲强磁场系统、粒子加速电磁发射 器等高精尖领域中对导体材料的需求; $380 \mathrm{~km} / \mathrm{h}$ 速 度的高速铁路电网接触线, 除了需要高导电性能外, 还应具有更高的强度、耐磨性和抗疲劳特性; 超大 规模集成电路用铜合金要求具有高强高导、耐热、 耐弯折、易刻蚀等特性。

（2）铜加工材料向细、薄、长和高精度的方向 发展。超细线、超薄带、薄壁管、超长管、超长带、 螺纹管、异形管、异形棒、异形带等产品的需求持 续增加, 如引线框架体现了多脚化、高密度化、超 薄、微型化的发展趋势。

（3）铜的高纯化。工业用铜的含铜量由 $99.9 \%$ 提高到 $99.95 \%$ ，再提高到 $99.99 \%$ 甚至更高，目的 是尽可能地提高材料的导电和导热性。含铜量为 99.999 9\% 的超纯铜, 将最大限度地减少杂质对导 电和导热性的影响。

（4）材料复合化。单一的材料强化方式潜力有 
限, 采用复合化的方法使铜材的综合性能得到进一 步提升成为研究热点。例如, 在铜合金中加入第二 相颗粒、晶须或纤维对铜基体进行复合强化, 开 发新型多功能铜基复合材料，对高性能铜合金的 设计理论与高新技术领域中的实际应用具有重要 价值。

\section{（二）面临的问题}

我国虽是世界铜合金材料第一大生产国，但依 然不是铜合金材料强国。我国航空航天、电子信息、 海洋工程、高端装备等众多高新技术领域亟需的高 性能铜合金仍较多依赖进口; 铜合金材料生产企业 众多、产业集中度低、产品竞争力弱、行业利润微 薄, 无法支撑高新技术产业发展。涉及的铜合金材 料产业问题主要如下。

(1) 高性能铜合金材料的品种和牌号少, 部分 高性能铜合金综合性能普遍低于同类进口产品, 如 自主研发生产的 Cu-Ni-Si、Cu-Cr-Zr 引线框架带材 牌号极少。

（2）大规格高品质铜合金产品的稳定生产能力 亟待提高, 如高精度弹性铜合金带材产品性能稳定 性、表面质量、综合成材仍待取得突破。

（3）高性能铜合金的加工过程环境污染大，资 源浪费较为严重; 高效短流程制备技术还不成熟, 产品质量和性能也待提高。

（4）部分高端生产装备的自主制造技术缺乏, 使得新产品开发受限, 如大部分高精度箔材生产装 备依赖进口。

(5) 部分高端铜合金材料缺乏自主知识产权和 公共研发平台, 材料性能、生产技术、标准规范等 方面的数据库建设滞后。

（6）超高纯、超低氧含量的无氧铜大规格均质 化制备技术仍待进一步完善, 高精度大口径长寿命 的耐蚀白铜制备技术有待深化突破。

\section{五、我国先进铜合金材料的发展路径}

\section{（一）中长期发展目标}

“十四五” 时期, 针对高端装备对于高性能、 高精度铜及铜合金板 / 带 / 箔材与管、棒、线的重 大需求, 在先进铜合金材料产业的产品性能提升、
绿色制造、产业升级、集成创新等方面进行重点突 破, 促进先进铜合金材料在国民经济关键领域的示 范和推广应用。重点开发新一代超高强高导电铜合 金及其复合材料, 进一步提升高端铜合金产品的性 能稳定性和产量。预期经过 5 15 年的努力, 构建 完整的先进铜合金材料绿色、高性能化制造产业体 系，整体技术水平迈入国际先进行列。

调整产业结构, 促进先进铜合金材料的绿色、 高端、智能化发展。(1)注重产品的定位调整优化, 坚持走绿色、高端发展之路, 向高性能化、高精 细化靠拢, 提高产品质量, 保障国内高端市场并 推动出口。(2)实现碎片化技术的集成, 建立铜合 金材料设计、加工、设备、应用等系统大数据库。 (3)通过技术研发与创新, 实现高端铜合金产品的 国产化，摆脱先进铜合金原材料受制于人的局面; 提高产品在重大工程领域中的应用比例, 提升产 品附加值。

完善自主创新体系, 促进高性能铜合金材料产 业可持续发展。(1)通过自主研发先进铜合金的体系、 制备和加工技术, 完善配套产业链, 建立自主创新 型的研发生产平台。(2)进一步整合资源, 加强先进 铜合金产业文化建设, 形成有效的 “产学研用管” 互动机制; 提高先进铜合金产业集群的国际化运营 水平, 实现健康、协调、稳定发展。

\section{（二）关键技术分析}

在先进铜合金材料的创新和制备技术方面，为 实施有效赶超并突破国产材料的制备技术瓶颈，应 进一步加强高端产品、先进制备加工装备及技术的 自主研发力度。这其中涉及了一系列关键技术。

(1) 先进铜合金材料体系建设。开展先进铜合 金材料 / 工艺/结构一体化设计, 基本形成具有知 识产权的先进铜合金材料体系和制备新技术体系。 以国家重点实验室、工程技术中心、检测中心的 形式建设先进铜合金创新平台、分析测试评价（标 准) 平台、产业化示范平台, 支持构建先进铜合 金自主创新能力。

（2）基于国家重大工程和新型产业需求、具有 先进铜合金自主知识产权的关键制备加工技术开发 及其产业化。主要内容包括: 高精度高纯无氧铜板/ 带/䇴材产业化生产技术、 $\mathrm{Cu}-\mathrm{Cr}-\mathrm{Zr}$ 系合金大盘重 
超长 (>1500 m) 接触线产业化生产技术、 $\mathrm{Cu}-\mathrm{Ni}-$ $\mathrm{Si}$ 系与 $\mathrm{Cu}-\mathrm{Cr}-\mathrm{Zr}$ 系合金大卷重 $(>8 \mathrm{t})$ 高精度超 薄框架带材产业化生产技术、弥散强化铜合金及 高导热低膨胀电子封装材料高致密无泄漏可靠特 种制备技术、高精度大规格高耐蚀铜合金产业化 生产技术、长寿命高耐磨环境友好型铜合金产业 化生产技术等。自主突破一批具有国际领先水平 的先进铜合金高效短流程制备加工技术，推动铜 加工业的整体技术进步。

\section{六、对策建议}

\section{（一）促进 “产学研用管” 统筹规划和一体化发展} 在政策引导与支持下，依据国家科技领域布 局，联合铜合金制备加工企业、科研院所、应用 单位实施 “产学研用管” 协同机制。集中 “产学 研用” 优势力量, 突破制约我国重大工程和新兴 产业发展的高端铜合金基础原材料产品的关键制 备加工技术，解决 “卡脖子” 问题，推进先进铜 合金制造强国的建设。建立和完善 “技术研发与 创新” “人才培养与引进” “信息与交流” “政策支 持与保障” 4 类平台，为先进铜合金产业集群发展 提供可靠且持续的技术和人才支撑，为创建国家 级产业开发区提供示范。

\section{（二）提升装备开发、技术研发和市场拓展能力}

借鉴国际先进经验和发展过程，依靠自主科技 创新，建立行业大数据来驱动铜及铜合金材料制造 全流程的智能控制工艺。以产业有关装备开发为核 心, 涵盖先进连铸连轧 (连挤) 机组、连拉连退机组、 连拉连镀机组、超细拉丝和丝退火镀覆 / 涂覆机组 等; 提高生产能力与生产效率, 降低能耗与原材料 损耗率，提升产品性能与质量稳定性，提高市场竞 争力与占有率。

\section{（三）强化产品标准研究与制定}

面向高端制造对先进铜合金材料综合性能的 要求, 建立和完善先进铜合金材料产品和生产技 术方面的标准体系。建立超细铜线（包括镀锡线 和漆包线)、特种铜基复合材料等新产品的国家或 行业技术标准，完善铜资源回收利用的标准与方
法, 从源头上规范秩序，确保行业的健康可持续 发展。

\section{（四）建立先进铜合金青年科技骨干人才培养体系} 丰富学术 / 技术研讨, 加强技术专家与青年科 技骨干的交流、军民协同应用对接、跨所有制的企 业合作。推行专家团队服务企业的 “引智” 模式, 群策群力为企业产品攻关建言献策, 以攻克具体技 术问题为目标开展专家服务生产 “精准扶贫”。建 设和提升 “老中青” 结合的先进铜合金人才队伍。

致谢

感谢参与中国工程院咨询项目《先进基础材料发展战略研究 报告 (有色金属类)》课题研究的米绪军、易健宏、钟云波、刘平、 梁淑华、张士宏、孟亮、吴玉程、谢明、牛立业、王文斌、赵红涁、 刘峰、王永如等同志的辛勤工作。

\section{参考文献}

[1] 李周, 肖柱, 姜雁斌, 等. 高强导电铜合金的成分设计、相变与制 备 [J]. 中国有色金属学报, 2019, 29(9): 2009-2049.

Li Z, Xiao Z, Jiang Y B, et al. Composition design, phase transition and fabrication of copper alloys with high strength and electrical conductivity [J]. The Chinese Journal of Nonferrous Metals, 2019, 29(9): 2009-2049.

[2] 干勇. 产学研深度融合推进制造强国创新体系建设 [J]. 中国科 技产业, 2019 (1): 14-15.

Gan Y. Deep integration of industry-university-research cooperation to promote the construction of manufacturing innovation system $[\mathrm{J}]$. Science \& Technology Industry of China, 2019 (1): 14-15.

[3] Dong Q Y, Wang M P, Shen L N, et al. Diffraction analysis of $\alpha$-Fe precipitates in a polycrystalline $\mathrm{Cu}$-Fe alloy [J]. Materials Characterization, 2015, 105: 129-135.

[4] 汪明朴, 贾延琳, 李周. 先进高强导电铜合金 [M]. 长沙: 中南大 学出版社, 2015.

Wang M P, Jia Y L, Li Z. Advanced high-strength conductive copper alloy [M]. Changsha: Central South University Press, 2015.

[5] Ouyang Y, Gan X P, Zhang S Z, et al. Age-hardening behavior and microstructure of $\mathrm{Cu}-15 \mathrm{Ni}-8 \mathrm{Sn}-0.3 \mathrm{Nb}$ alloy prepared by powder metallurgy and hot extrusion [J]. Transactions of Nonferrous Metals Society of China, 2017, 27(9): 1947-1955.

[6] Tang S K, Li Z, Gong S, et al. Mechanical property and corrosion behavior of aged $\mathrm{Cu}-20 \mathrm{Ni}-20 \mathrm{Mn}$ alloy with ultra-high strength [J]. Journal of Central South University, 2020, 27(4): 11581167.

[7] Xiao Z, Huang Y J, Chen C X, et al. Effects of thermal treatments on the residual stress and micro-yield strength of $\mathrm{Al}_{2} \mathrm{O}_{3}$ dispersion strengthened copper alloy [J]. Journal of Alloys and Compounds, 2019, 781(15): 490-495.

[8] 袁远. 高速铁路用 $\mathrm{Cu}-\mathrm{Mg} 、 \mathrm{Cu}-\mathrm{Cr}$ 合金连续挤压组织性能研究 
[D]. 长沙: 中南大学(博士学位论文), 2017.

Yuan Y. Microstrcture and properties of $\mathrm{Cu}-\mathrm{Mg}$ and $\mathrm{Cu}-\mathrm{Cr}$ alloys after Conform process [D]. Changsha: Central South University(Doctural dissertation), 2017.

[9] Li J, Huang G J, Mi X J, et al. Microstructure evolution and properties of aquaternary $\mathrm{Cu}-\mathrm{Ni}-\mathrm{Co}-\mathrm{Si}$ alloy with high strength and conductivity [J]. Materials Science and Engineering: A, 2019, 766(24): 1-12.

[10] 杨广英, 徐超, 宋瑞, 等. 电气化铁道用铜及铜合金绞线 TB/T
2809-2017 [S]. 北京: 国家铁路局, 2017.

Yang G Y, Xu C, Song R, et al. Copper and copper-alloy stranded conductors for electric railway TB/T 2809-2017 [S]. Beijing: National Railway Administration of the People's Republic of China, 2017.

[11] Huang J Z, Xiao Z, Dai J, et al. Microstructure and properties of a novel Cu-Ni-Co-Si-Mg alloy with super-high strength and conductivity [J]. Materials Science and Engineering: A, 2019, 744(28): 754-763. 